\title{
AQUAPONIA: PRODUÇÃO DE PEIXES E VEGETAIS
}

\section{AQUAPONICS: FISH AND VEGETABLE PRODUCTION}

\author{
Marcelo Batista da Silva ${ }^{1}$; Renato Miguel L. Moscoso Pessôa ${ }^{2}$; Willian Ivaldo de Moura ${ }^{3}$; \\ Ricardo José Araújo Miranda ${ }^{4}$; Willy Vila Nova Pessoa ${ }^{5}$
}

DOI: https://doi.org/10.31692/978-65-991061-7-0.486-489

\section{INTRODUÇÃO}

A aquaponia é um sistema de produção de alimentos que integra a hidroponia e a aquicultura (Carneiro et al. 2015). Nesse sistema há um aproveitamento dos resíduos produzidos pela piscicultura para os vegetais crescerem e frutificarem quando assimilam os nutrientes resultantes da alimentação e excreção dos peixes que são bioconvertidos por nitrificação de bactérias aeróbias (Nitrossomonas e Nitrobacter) (Knaus \& Palm 2017).

Nesse sistema há o reuso de $90 \%$ da água comparado a piscicultura tradicional. Como resultado (FERREIRA, D.F.), a aquaponia produz menor quantidade de efluente para o meio ambiente. Além disso, têm demonstrado ser uma alternativa eficiente para pequenos produtores e associações, com manejo simplificado visando uma produção em pequena e larga escala. É um consenso entre diversos pesquisadores e investidores no mundo e no Brasil que a aquaponia é uma alternativa de alimentação viável, saudável e de bem-estar no âmbito social, além de ser uma alternativa ecologicamente correta para produção de alimentos livres de agrotóxicos.

Nesse sentido, a produção de peixes e vegetais podem ser produzidos como alimentos orgânicos dependendo da forma de alimentação dos peixes e geração dos nutrientes essenciais para as plantas. A produção de vegetais na aquaponia tem sido apontada como uma alternativa "ecologicamente correta" para a aquicultura dos dias atuais (KANO et al. 2012). Outra característica positiva é que na aquaponia não se utiliza agrotóxicos. No Brasil, o uso indiscriminado de agrotóxicos representa uma ameaça à saúde de consumidores desses produtos oriundos do agronegócio.

\section{RELATO DE EXPERIÊNCIA}

\footnotetext{
${ }^{1}$ Curso Técnico em Agricultura, IFPE, campus VSA, e-mail: solahez@gmail.com

${ }^{2}$ Curso Superior de Agronomia, IFPE, campus VSA, e-mail: renatomoscoso@gmail.com

${ }^{3}$ Curso Técnico de Zootecnia, IFPE, campus VSA, e-mail: wyllyanmoura400@gmail.com

${ }^{4}$ Doutor em Engenharia Agrícola, IFPE, campus VSA, e-mail: ricardo.araujo@ vitoria.ifpe.edu.br

${ }^{5}$ Doutor em Recursos Pesqueiros e Aquicultura, IFPE, campus VSA, e-mail: willy.vilanova@vitoria.ifpe.edu.br
} 
O estágio é uma ferramenta de aprendizado importante para a formação acadêmica do estudante de nível técnico, uma vez que estimula o desenvolvimento de técnicas aliando a teoria vivenciados na sala de aula à prática no campo. O presente trabalho foi realizado com o objetivo de vivenciar o cultivo de peixes e vegetais (aquaponia) (KNAUS \& PALM 2017), aquaculture.2016.09.025 em um sistema NFT (Nutrient Film Technique) utilizando canaletas apoiadas em uma mesa com 135 furos no total (Figura 1).

Figura 1. Bancada com canaletas (NFT), tanque de cultivo com 1.000 litros equipados com decantador e biofiltro 100 litros cada.

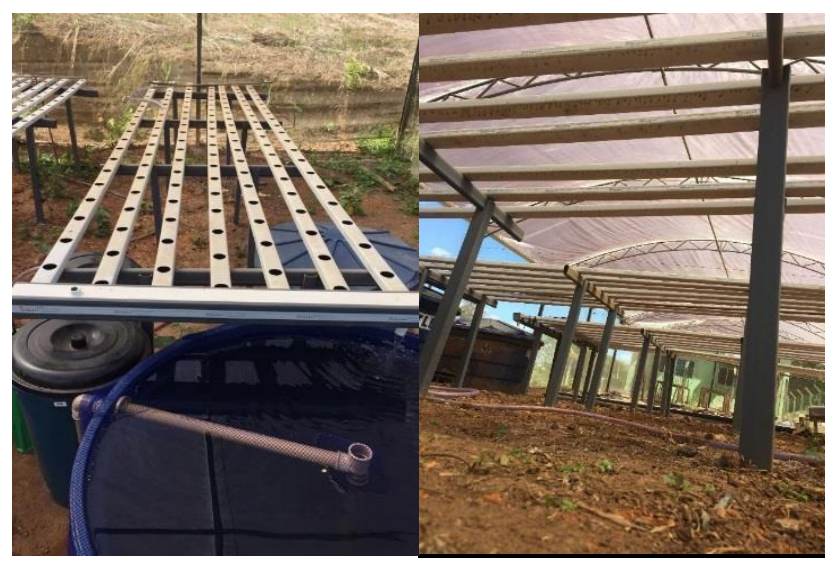

As atividades foram desenvolvidas numa estufa de $200 \mathrm{~m}^{2}$ localizada no Instituto Federal de Educação, Ciência e Tecnologia de Pernambuco (IFPE) - Campus Vitoria de Santo Antão. O início do cultivo foi realizado no dia 11 de setembro de 2018, totalizando 30 dias.

Ao todo foram utilizadas, 113 mudas, sendo 21 pés de alface lisa, 31 pés de alface americana e 61 pés de tomate cereja. Os tomates cereja foram mantidos como local temporário até a montagem de um sistema maior ideal para o seu cultivo. Todas as mudas foram doadas por produtores. Durante a vivência foi possível ter experiências com visitas guiadas de estudantes da rede estadual de ensino, participação em feiras do agronegócio orgânico e visitas técnicas de professores do IFPE e de outras instituições de ensino da rede federal.

Durante as atividades diárias foi possível participar de diferentes atividades: instalação do sistema, manejo alimentar, mensurar o $\mathrm{pH}$ da água, e realizar o controle biológico do ambiente, além de verificar todo o funcionamento da aquaponia (canos, bombas, compressores de ar, entre outros).

Alguns desafios na manutenção do sistema foram observados durante o cultivo. Os mais importantes foram àqueles relacionados ao dimensionamento do sistema de filtragem (biofiltros) com $10 \%$ do volume útil do cultivo de peixes, cálculo de biomassa viva (peixes) em função da percentagem de alimentação com ração balanceada (32\% de Proteína Buta), 
além do controle da limpeza nos tanques de cultivo dos peixes (Tilápia do Nilo, Oreochromis niloticus), no tanque de 1000 litros foram utilizados 70 peixes de peso médio de 25 gramas.

Durante o cultivo houve alguns sinais aparentes de deficiência nutricional das alfaces. Possivelmente por carência do ferro (Fe), o qual é um dos micronutrientes mais importantes para o fortalecimento da planta. Um dos fatores de produção que requer uma maior atenção no sistema é a eficiência do biofiltros, além da capacidade de decantação dos sólidos em suspensão na água. Para que ocorra a absorção dos nutrientes pelas plantas há a necessidade de bioconversão da amônia, em nitrito e nitrato no biofiltro por bactérias nitrificantes. Além disso, é essencial manter a oxigenação do biofiltro através de compressor de ar (21/ min). Cuidando desses fatores é possível obter um crescimento rápido dos peixes e plantas.

A dificuldades do cultivo nesse primeiro ciclo experimental no IFPE foram diversas, entretanto todas as dificuldades encontradas podem ser ajustadas para aumentar a eficiência de produção. Os vegetais obtiveram êxito no crescimento apesar das deficiências nutricionais reforçando que em meio a improvisos e falta de experiência a aquaponia é possível de ser realizada. O crescimento vegetal pode ser visto na Figura 2 (início e fim do cultivo).

Figura 2. Foto da esquerda em 11/09/2018 e foto da direita em 06/10/2018 totalizando 25 dias de cultivo.

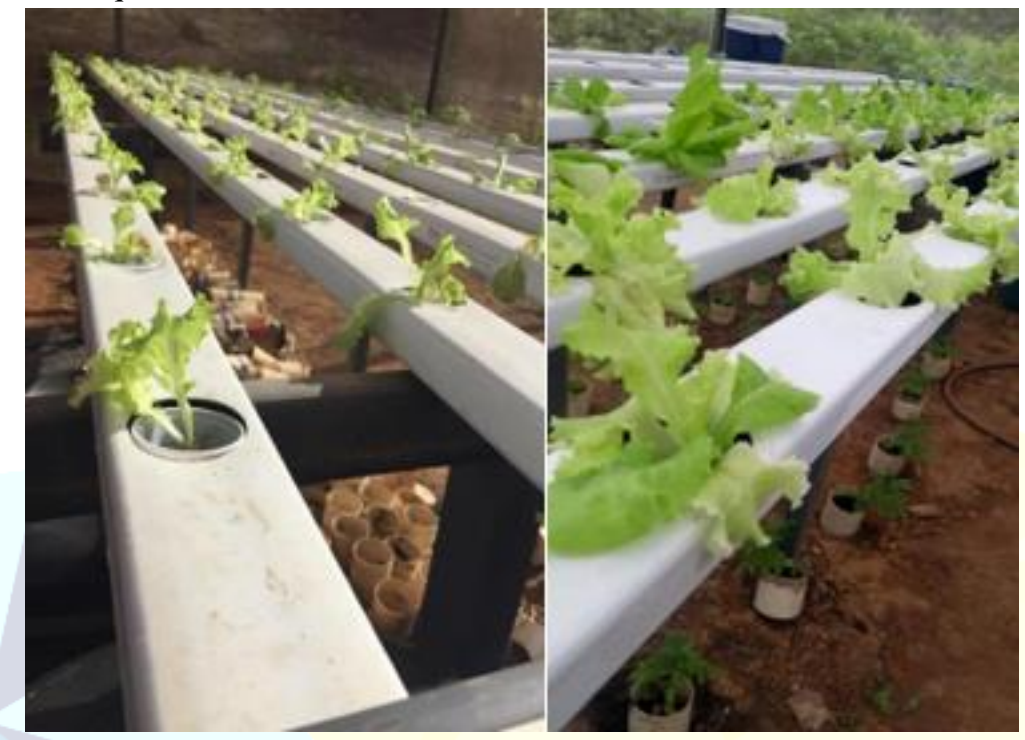

Como parte das atividades de desenvolvidas foram realizadas participações em feiras pernambucanas (feira da farinha/ Aliança; Expo Goitá/ Glória de Goitá e em Vitória de Santo Antão) direcionada ao produtor rural e ao mercado comum consumidor de hortaliças orgânicas. Essa experiência reforça a necessidade de formulação de projetos de extensão para difusão da tecnologia da aquaponia entre produtores afim de desenvolver o setor e criar uma alternativa de renda para os produtores rurais e urbanos. 


\section{CONSIDERAÇÕES}

A aquaponia é uma alternativa viável para o produtor que tem interesse em alimentos orgânicos alto valor nutricional e livre de químicos nocivos à saúde. Como experiência dessa vivência podemos concluir que é importante: (i) maturar o biofiltro por pelo menos 30 dias ou mais para estabilização das bactérias para produção dos nutrientes; (ii) selecionar peixes com tamanho uniforme para determinação mais precisa da taxa de arraçoamento; (iii) calcular a taxa de arraçoamento (\% da biomassa viva) forma precisa para a determinação da quantidade de nutrientes, principalmente do nitrogênio e fósforo ( $\mathrm{N}$ e $\mathrm{P}$ ) provenientes dos peixes (fezes e urina), e; (iv) os peixes são parte da produção secundária nessa escala experimental, embora seja possível escalonar uma produção comercial (larga escala) para venda do pescado no mercado junto com as hortaliças;

\section{REFERÊNCIAS}

CARNEIRO. P. C. F.,MORAIS, C.A.R.S, NUNES, M.U.C., MARIA, A.N., FUJIMOTO, R.Y. Produção integrada de peixes e vegetais em aquaponia. Embapa Tabuleiros Costeiros, 2015. (Documento / Embrapa Tabuleiros Costeiros (ISSN 1678-1937, 189). 27p. 2015 .

FERREIRA, D.F. Sivar: a computerstatisticalalysis system. Ciência e Agrotecnologia Lavras, v.35, n.6, p.1039-1042, 2011.

KANO, C.; CARDOSO, A. I. I.; VILLAS BÔAS, R. L. Acúmulo de nutrientes e resposta da alface à adubação fosfatada. Revista Biotemas, Florianopolis, v.25, n.3, p.39-47, set. 2012 .

KNAUS U, PALM HW (2017) Effects of fish biology on ebb and flow aquaponical cultured herbs in northern Germany (Mecklenburg Western Pomerania). Aquaculture 466:51-63. 